\title{
Mentoring Requires Trust
}

Arch G. Mainous III, PhD

(Fam Med. 2021;53(3):173-4.)

doi: 10.22454/FamMed.2021.517439

D eveloping young faculty in family medicine departments is important because it helps the person, the organization, and the discipline. While there are multiple strategies in the toolbox for career development, Dean Seehusen, MD, MPH, and colleagues in this issue highlight mentoring, sponsoring, and coaching from the experiences of a sample of family medicine department chairs. ${ }^{1}$ The majority of these chairs had received career help through these strategies and were using these same approaches with their faculty. They are paying it forward.

One unstated critical issue is the relationship between those offering help and those receiving it. The relationship and communication between mentor and the faculty member is a dynamic that must be based on honest communication. Mentoring books often focus on mentors and mentees matching based on shared interests. ${ }^{2}$ This voluntary matching is prevalent in basic science laboratories. However, many family medicine departments utilize assigned mentors for junior faculty. Inexperienced department chairs may feel responsible for the development of all of the faculty in their department and may seek to provide this directly. In such cases, from the chair's perspective, mentoring can become an arranged marriage between the mentor (the chair) and the mentee (faculty member). In larger departments, mentoring usually becomes less centralized. But in all cases, the relationship between faculty members and their mentors and sponsors depends on trust and honest communication.

How do the goals of each faculty member evolve and to what extent do they match organizational goals? Honest communication is imperative for success on both sides. Not everyone can be the residency director or clerkship director. So, the skill set and temperament of the mentee may be inconsistent with their own career goals. Furthermore, goals can change dramatically over time. Some faculty members think that they want to become National Institutes of Health-level investigators but, after working toward that goal, decide that they are more interested in developing as an educator or administrator. It is important that the mentee feels valued and gets the opportunities that they need for development, but at the same time giving honest advice helps them to be on the track where they are most likely to succeed. Thus, new opportunities and sources of support will be needed when faculty goals change. Again, this revised track needs to be pursued in consonance with the organization's needs. Constant communication and realistic expectations need to underpin faculty development efforts.

Honest communication helps to build trust. Does the mentee feel that the chair is acting in the mentee's best interest? Sponsorship is a good tool for chairs to use with junior faculty. In fact, chairs are often well placed to effectively utilize this strategy by recommending faculty for college or university committees, journal editorial boards, or even committee memberships at national organizations. Appointment to such roles is a great way to move a career forward. Someone who is well known in the field can play a critical role in introducing and sponsoring someone who is junior and less well known. We have all been to our first Society of Teachers of Family Medicine Annual Spring Conference reception and watched groups of people in lively conversation and felt 
hesitant to join in conversation with people we had never met. Having someone introduce you and include you makes a world of difference in transforming the experience from lonely to fun. Those new connections can lead to a whole host of new collaborative opportunities that can enhance the careers of junior faculty members.

Honest communication also helps to guide the mentor in suggesting the right meetings to attend and the right committee appointments for mentees to meet the career goals of the mentee as well as the department's needs. Some faculty play unique roles in the department. A one-size-fits-all approach is not in the best interest of the mentee or the department. Helping each person to develop in ways consistent with their own goals and with the department's needs requires an honest and open interaction. For example, it is important to help nonclinical faculty members to see family medicine as their home, but they are better suited for some committees and organizations and roles in their departments than others. ${ }^{3}$ The mentor/sponsor must listen and then link realistic aspirations with training opportunities.
In sum, there are many tools in the faculty development toolbox for chairs and mentors. Honest communication between the mentor and the mentee about goals and priorities will help both the faculty member and the department prosper.

CORRESPONDENCE: Address correspondence to Dr Arch G. Mainous III, Department of Health Services Research, Management and Policy, University of Florida, Health Sciences Center, PO Box 100195, Gainesville, FL 32610. 352-273-6073. Fax: 352-273-6075. arch.mainous@ufl.edu.

\section{References}

1. Seehusen D, Rogers T, Al Achkar M, Chang T. Coaching, mentoring, and sponsoring as career development tools. Fam Med. 2021;53(3):175-180. doi: 10.22454/FamMed.2021.341047

2. National Academy of Engineering. Adviser, Teacher, Role Model, Friend: On Being a Mentor to Students in Science and Engineering. Washington, DC: The National Academies Press; 1997. doi:10.17226/5789

3. Wilson S, Mainous AG III, O'Donnell C, Bateman H. The integral role of non-clinical academics in meeting the goals of primary care training and research. Fam Pract. 2005;22(4):355-357. doi:10.1093/fampra/cmi017

\section{New Instructions for Authors}

Family Medicine has completed a major revision of our Instructions for Authors. The new instructions are available on our website (https://journals.stfm.org/media/3713/2021-fm-authors-instructions.pdf).

There are four major changes to this document. All potential authors should carefully review the new instructions when preparing manuscripts for submission. The four major changes are:

1. We have described how we will use the taxonomy described by Kirkpatrick to evaluate the rigor of evaluation methods used in educational research papers (original articles and brief reports). Effective immediately, we will give preference to research papers using higher levels of evaluative rigor.

2. We have specified new guidelines for the use of language to categorize racial and ethnic groups in research papers.

3. We have listed specific criteria that we will use in evaluating survey research papers.

4. We have more clearly described our expectations for formatting tables and figures in research papers.

Our editorial team views these changes as a clarification of review processes already in use. We hope they will help potential authors to better understand our peer-review process. 